\title{
Prediction of Suicide Ideation and Attempt Among Substance-Using Patients in Primary Care
}

\author{
Kevin A. Hallgren, PhD, Richard K. Ries, MD, David C. Atkins, PhD, \\ Kristin Bumgardner, BS, and Peter Roy-Byrne, MD
}

Background: Suicide is a major public health concern, particularly among people who use illicit substances and/or non-prescribed medications.

Methods: The present study prospectively assessed the incidence and predictors of suicidal ideation (SI) and suicide attempt (SA) among 868 substance-using patients over 12 months after receiving primary care within seven public primary care clinics.

Results: Participants reported a high incidence of SI (25.9\%) and SA (7.1\%) over the year following primary care visits. Suicidality was elevated in patients who were female; lacked a high school diploma; were unemployed; reported depression, anxiety, hallucinations, concentration difficulty, or violent behavior; used nicotine or stimulants; used the emergency department or mental health services in the past 90 days; reported current quality-of-life impairment in mobility or usual activities; or reported recent SI or lifetime SA at baseline. In multiple regression analyses, only past 30-day SI, any lifetime SA, past 90-day violent behavior, and current impairment due to anxiety or depression at baseline uniquely predicted SI or SA beyond other variables.

Conclusions: Results support the need for screening for suicidality among primary care patients who use illicit substances and identify key subgroups of these patients who are at particularly elevated risk for suicidality. (J Am Board Fam Med 2017;30:150-160.)

Keywords: Anxiety, Depression, Follow-up Studies, Mental Health Services, Primary Health Care, Public Health, Quality of Life, Regression Analysis, Street Drugs, Substance-Related Disorders, Suicidal Ideation, Suicide

Annually, over 40,000 people in the United States die from suicide, ${ }^{1}$ and the annual rate of completed suicides has increased by $24 \%$ over the past 15 years. ${ }^{2}$ Suicide is currently the 10th leading cause of death and creates annual costs of $\$ 44$ billion. $^{3}$ Primary care providers are uniquely positioned to address health concerns related to suicidality. Three fourths of individuals who attempt or complete suicide interact with primary care providers in the 6 months before their suicide or attempt, whereas fewer than half receive psychiatric services within the same time period. ${ }^{4}$

This article was externally peer reviewed.

Submitted 17 August 2016; revised 20 October 2016; accepted 15 November 2016.

From the Department of Psychiatry and Behavioral Sciences, University of Washington School of Medicine, Seattle.

Funding: This study was funded by the National Institute on Drug Abuse (grant R01DA026014) and the National Institute on Alcoholism and Alcohol Abuse (grant K01AA024796 and T32AA007455).
Unfortunately, little is known about the incidence and predictors of suicidality among primary care patients who use substances. In the general population, alcohol or drug use disorders increase the risk for suicide by a factor of 10 to $14^{5-7}$, and the risk of suicidal ideation (SI) or suicide attempt (SA) for individuals with substance use disorders is only slightly lower than for individuals with mood or anxiety disorders. ${ }^{8}$ Alcohol and drug use disorders themselves are increasingly common presenting problems in primary care': people with alcohol or drug use disorders have high rates of comorbid health problems ${ }^{10}$ and are nearly twice as likely to

Conflict of interest: none declared.

Disclaimer: The content is solely the responsibility of the authors and does not necessarily represent the official views of National Institute on Drug Abuse, National Institute on Alcoholism and Alcohol Abuse, or the National Institutes of Health.

Corresponding author: Kevin A. Hallgren, PhD, 1959 NE Pacific Street, Box 356560, Seattle, WA (E-mail: khallgre@uw.edu). 
interact with general medical providers than specialty mental health providers within a typical $12-$ month period. ${ }^{11}$

Previous studies of substance-using populations have found greater suicidality risk among individuals with co-occurring depression and other mental health problems, ${ }^{5,12-14}$ heavier substance use, ${ }^{5,15-18}$ medical conditions, ${ }^{5}$ female sex,${ }^{5,13,15}$ previous violent behavior, ${ }^{19}$ and a history of suicide attempts. ${ }^{13,15}$ However, suicidality among substanceusing primary care patients is understudied; most studies typically focus more on alcohol than other drugs, use cross-sectional designs, assess suicidality retrospectively, or focus on community or specialty addiction treatment populations rather than primary care. The aim of this study was to address these gaps by prospectively characterizing the incidence and predictors of SI and SA over a 1-year period after attending primary care appointments for patients reporting use of illicit drugs or nonprescribed medications within the past 90 days.

\section{Methods \\ Design Overview}

This study is a secondary analysis of data from a randomized clinical trial of screening, a brief intervention, and referral to treatment for substance use in primary care. ${ }^{20,21}$ Participants $(n=868)$ received a single brief intervention using motivational interviewing, typically on the same day as their primary care appointments, with an attempted 10-minute telephone booster 2 weeks later $(n=435)$ or enhanced care as usual $(n=433)$, consisting of substance use screening, a handout showing screening results and associated risk factors, and a list of referrals to substance abuse treatment services.

Participants usually completed screening and baseline assessments on the same day as their primary care appointments. The screen included 2 items to assess use of illicit drugs and nonprescribed medications within the past 90 days. Baseline interviews further assessed eligibility criteria and information about substance use, psychiatric symptoms, and health-related impairment (described below). Measures were intentionally brief to mirror those that could be implemented in primary care, and variables included for this analysis were selected to represent the breadth of domains assessed in the baseline interviews.

SI and SA were reassessed 3, 6, 9, and 12 months after baseline primary care appointments. Inter- views were conducted in person whenever possible, with phone interviews as a backup option. Interviewers received extensive training on all measures, were observed during initial interviews to ensure adherence, and attended weekly supervision meetings throughout the study that addressed assessment quality and adherence. Full details of the study design and the main outcomes of the clinical trial are presented elsewhere ${ }^{20,21}$; in brief, there were no differences in substance use outcomes between treatment conditions, and both conditions had small reductions in substance use during the follow-up period compared with baseline. All participants provided written, informed consent. The study was approved by institutional review and data safety monitoring boards.

\section{Sample}

Participants were recruited from waiting rooms of 7 primary care clinics in King County, Washington. These clinics are part of a large, urban medical center and are considered safety-net clinics in that they serve a large number of patients who have a low income and limited or no health insurance. Few patients in this setting formally seek substance use treatment, and many patients have several suicide risk factors (eg, high rates of physical and psychiatric illness, ${ }^{22-24}$ low income and/or unemployment, ${ }^{25}$ homelessness, and previous SI and $\left.\mathrm{SA}^{23,26}\right)$.

In addition to drug use within the past 90 days, inclusion criteria included age $\geq 18$ years, speaks English, sixth-grade literacy, telephone or E-mail access, and plans to continue receiving care at the clinic. Exclusion criteria included formal substance abuse treatment in the past month (excluding 12step groups such as Narcotics Anonymous), lifethreatening medical illness, severe cognitive impairment, active psychosis, and imminent suicidal intent with a reported inability to control suicidal impulses. Seven patients were deemed ineligible before baseline because of imminent suicidal intent and were instead linked with appropriate clinical services; a full breakdown of other reasons for exclusion is available in the primary outcome study. ${ }^{21}$

\section{Measures \\ Suicidality}

SI and SA were assessed using 2 items from the Addiction Severity Index-Lite (ASI) ${ }^{27}$ indicating any serious SI in the past 30 days and any SA in 
one's lifetime (baseline) or SA since the last research assessment (follow-ups). The threshold for endorsing the SI item required that a patient "seriously considered a plan for taking his/her life." The SA item required at least 1 specific self-harming behavior with some intention of dying, regardless of the actual lethality of the method. For safety purposes, patients who endorsed SI received additional risk assessment and were linked with appropriate clinical services during or after the interviews.

Substance Use, Demographics, and Psychiatric Symptoms The ASI assessed the frequency of alcohol, opiate, sedative/hypnotic/tranquilizer, stimulant, marijuana, nicotine, hallucinogen, and other drug use over the past 30 days. Participants estimated the number of days among the past 30 that they used each illicit or nonprescribed drug class; 2 dichotomous variables were computed for each class, indicating any use or daily use within the past 30 days. ASI composite indices of alcohol and drug use severity were also computed; scores ranged from 0 (lowest severity) to 1 (highest severity).

The ASI assessed demographic variables including age, sex, race, ethnicity, marital status, and education. Psychiatric symptoms that did not directly result from substance use were measured on the ASI via single-item questions assessing depression, anxiety, hallucinations, difficulty concentrating, and difficulty controlling violent behavior within the past 30 days.

\section{Drug Use Severity}

The Drug Abuse Screening Test ${ }^{28}$ was administered at baseline to assess symptoms of nonalcohol drug use disorders over the past 12 months. The measure contains 10 yes/no items that are summed to create a single index of drug use severity; it has good reliability and criterion validity. ${ }^{28}$

\section{Employment and Social Variables}

Interviewers assessed at baseline whether participants experienced homelessness or incarceration within the past 90 days and whether they received welfare benefits within the past 30 days. Electronic state patrol records were reviewed for pending legal charges.

\section{Clinical Services Use}

Electronic medical records were reviewed from state inpatient hospitals, the medical center where the study took place, and state chemical dependency treatment facilities to assess emergency department, mental health, substance abuse, and outpatient medical treatment use within the past 90 days. Interviewers also assessed participation in 12step groups within the past 90 days.

\section{Health-Related Quality of Life}

The European Quality of Life Scale (EuroQol) ${ }^{29}$ assessed current health-related impairments in mobility, self-care, activities, pain, and anxiety/depression at baseline. Patients also rated their overall perceived health status using a visual-analog health scale (VAHS), from 0 (worst imaginable) to 100 (best imaginable).

\section{Statistical Analyses}

All analyses used binary outcomes reflecting any SI or SA within the 12-month follow-up. Summary variables were computed to reflect whether SI or SA were present at least once over the full 12month follow-up. Outcomes were measured differently for SI (past 30 days) and SA (since the last assessment) at each follow-up, and indicators were computed to indicate whether any SI or any SA was known to be present on at least 1 occasion, absent throughout the entire follow-up period that was assessed, or unknown because of missing followups. (SI was coded as missing if participants did not endorse SI at any of the completed follow-ups and missed one or more follow-up, in which case SI within the past month in all 4 periods could not be known. SA was coded as missing if participants did not endorse SA at any of the completed follow-ups and also did not complete the 12-month follow-up, in which case SA over the full 12-month period could not be known.)

Although it is not possible to definitively evaluate why follow-up data were missing, we examined SI and SA at baseline as predictors of "missingness" and found that missing follow-up SI data were more common for participants without baseline SI $(18.1 \%)$ than for participants with baseline SI $(8.7 \% ; P=.003)$; missing data were unrelated to baseline SA. To address missing data, in all statistical analyses we used multiple imputation with chained logistic regression equations, ${ }^{30}$ which re- 
duces bias more than other approaches, even when some data are not missing at random. ${ }^{31}$ Twenty imputation sets were generated using Gibbs sampling, incorporating all baseline variables (including baseline SI and SA) to improve prediction accuracy.

Descriptive statistics were computed to estimate the incidence of SI and SA over the 12-month follow-up period. Single-predictor logistic regression tested univariate associations of baseline variables with SI and SA over the 12-month follow-up. Significant univariate predictors $(P<.05)$ were then entered into logistic multiple regression models to identify the relative importance of predictors when accounting for other predictors. All analyses were conducted using $\mathrm{R}$ software. ${ }^{32}$

All predictors except age, ASI severity indices, and EuroQol/VAHS were dichotomized to indicate that a symptom or characteristic was present (1) or absent (0). The remaining continuous variables (age, ASI severity, EuroQol/VAHS) were standardized as $z$-scores. Treatment condition was not entered into statistical models because of the lack of association with subsequent SI and SA $(P \geq .86)$.

\section{Results}

\section{Baseline Characteristics}

Among the 868 patients with data at baseline, $12.1 \%$ endorsed SI within the past 30 days and $39.6 \%$ reported SA within their lifetime (Table 1; predictors of SI within the past 30 days and SA over the lifetime at baseline for this sample have been reported elsewhere ${ }^{14}$ ). Table 1 presents other descriptive statistics including demographics, employment, social issues, psychiatric symptoms, suicidality, substance use, health care utilization, and health-related quality of life. Participants were predominantly male and unmarried. Other demographics reflected the diversity of patients served by these clinics, including a high percentage who were unemployed and receiving welfare. Over a third were white and another third were African American. A majority endorsed feeling depressed or anxious, about half reported difficulty concentrating, and nearly four-fifths endorsed at least moderate pain or discomfort.

Marijuana, nicotine, alcohol, and stimulants were the most commonly used substances. Hallucinogen and "other" drug use within the past 30 days was endorsed by only 19 participants (2.2\%) and 33 participants $(3.8 \%)$, respectively, with daily use endorsed by 0 and 1 participant, respectively; therefore, these drug classes were not included in subsequent analyses. Of note, just under half of the patients had emergency treatment within the past 90 days. Only 1 in 4 participants received mental health care in the past 90 days; fewer reported 12 -step involvement or formal substance use treatment during the same time window.

\section{2-Month SI and SA Incidence}

Within the full sample of 868 participants, data on SI (within the past 30 days at months 3, 6, 9, and 12) and SA (throughout the full 12-month period) were available for 721 and 780 participants, respectively. As shown in Table 2, SI was endorsed on at least 1 occasion over the 12 -month period by $25.9 \%$ of the sample, whereas SA was endorsed by $7.1 \%$ within the same period. Of participants who endorsed SI during follow-up, $21.1 \%$ also endorsed SA during the follow-up, whereas $73.1 \%$ of those who endorsed SA during follow-up also endorsed SI. Of note, most participants who endorsed SI $(52.9 \%)$ or SA $(78.2 \%)$ during the full follow-up period did so on only 1 of the 4 follow-up assessments, suggesting that those who endorsed SI or SA were not consistently suicidal over the full 12month period.

\section{Univariate Predictors of SI and SA}

Associations between individual baseline variables and SI and SA incidence within the full 12-month follow-up period are presented in Table 3. Odds ratios reflect the increase in odds of subsequent 12 -month SI or SA when a predictor variable is present (binary predictors) or when a predictor variable increases by 1 standard deviation (continuous predictors) without controlling for other baseline variables.

\section{Suicidal Ideation}

Among all baseline predictors, SI within the past 30 days and any SA in a lifetime were associated with the highest increased odds of subsequent 12-month SI. SI was unrelated to sex or education status and was less common among African Americans and patients reporting alcohol use at baseline. Unemployed patients had higher odds of SI, as did patients endorsing any psychiatric symptoms assessed in the ASI (depression, anxiety, hallucinations, dif- 
Table 1. Baseline Sample Characteristics $(\mathrm{N}=868)$

\begin{tabular}{|c|c|}
\hline Baseline Variables & \\
\hline \multicolumn{2}{|l|}{ Demographic } \\
\hline Age (years), mean (SD) & $47.76(10.89)$ \\
\hline Female sex & $264(30.4)$ \\
\hline White & $386(44.5)$ \\
\hline African American & $320(36.9)$ \\
\hline Other race* & $162(18.7)$ \\
\hline Hispanic ethnicity (any race) & $72(8.3)$ \\
\hline High school graduate & $701(80.9)$ \\
\hline Married or cohabitating & $154(17.8)$ \\
\hline \multicolumn{2}{|l|}{ Employment and social } \\
\hline Unemployed & $655(75.7)$ \\
\hline Receiving welfare & $606(69.9)$ \\
\hline Waiting legal charges & $54(6.3)$ \\
\hline Jail in the past 90 days & $51(5.9)$ \\
\hline Homeless in the past 90 days & $263(30.4)$ \\
\hline \multicolumn{2}{|l|}{ Psychiatric symptoms } \\
\hline Depression & $548(63.1)$ \\
\hline Anxiety & $559(64.4)$ \\
\hline Hallucinations & $80(9.2)$ \\
\hline Concentration & $426(49.1)$ \\
\hline Violent behavior & $134(15.4)$ \\
\hline \multicolumn{2}{|l|}{ Suicidality } \\
\hline Suicidal ideation in the past 30 days & $104(12.0)$ \\
\hline Suicide attempt during lifetime & $345(39.8)$ \\
\hline \multicolumn{2}{|l|}{ Substance use in the past 30 days } \\
\hline Any alcohol & $598(68.9)$ \\
\hline Daily alcohol & $67(7.7)$ \\
\hline Any opiate & $228(26.3)$ \\
\hline Daily opiate & $11(1.3)$ \\
\hline Any sedative & $72(8.3)$ \\
\hline Daily sedative & $39(4.6)$ \\
\hline Any stimulant & $362(41.7)$ \\
\hline Daily stimulant & $24(2.8)$ \\
\hline Any marijuana & $656(75.6)$ \\
\hline Daily marijuana & $145(16.7)$ \\
\hline Any nicotine & $620(71.6)$ \\
\hline Daily nicotine & $454(52.4)$ \\
\hline Any injection drug use & $39(4.5)$ \\
\hline Addiction Severity Index, mean (SD) & $0.15(0.20)$ \\
\hline \multicolumn{2}{|l|}{ Alcohol score } \\
\hline Drug score & $0.13(0.11)$ \\
\hline $\begin{array}{l}\text { Days using alcohol or drugs (of the past } \\
\text { 30), mean (SD) }\end{array}$ & $15.39(11.45)$ \\
\hline \multicolumn{2}{|l|}{$\begin{array}{l}\text { Medical and psychiatric treatment in the } \\
\text { past } 90 \text { days }\end{array}$} \\
\hline Substance use treatment & $61(7.1)$ \\
\hline 12-Step participation & $146(16.8)$ \\
\hline Emergency department & $386(44.5)$ \\
\hline Medical visit & $701(81.1)$ \\
\hline Psychiatric outpatient & $227(26.2)$ \\
\hline
\end{tabular}

Continued
Table 1. Continued

Baseline Variables

Health-related quality of life

Mobility impairment

$481(55.5)$

Self-care impairment

$138(15.9)$

Usual activity impairment

$404(46.7)$

Pain

$677(78.2)$

Anxiety or depression

$456(52.7)$

Visual-Analogue Health Scale score, mean (SD)

$61(22.8)$

Data are $\mathrm{n}(\%)$ unless otherwise indicated.

* "Other race" included 93 participants (10.7\% of sample) who were multiracial, 28 (3.2\%) who were American Indian or Alaska Native, 10 (1.2\%) who were Asian, 6 (0.7\%) who were Native Hawaiian or Pacific Islander, and 25 (2.9\%) with unknown or other race.

SD, standard deviation.

ficulty concentrating, violent behavior) and patients with outpatient psychiatric care within the past 90 days. Daily stimulant use and higher baseline ASI drug scores were associated with higher odds of subsequent SI, as were impairments in mobility, usual activities, or anxiety/depression on the EuroQol. Better perceived health status was associated with lower odds of SI.

\section{Suicide Attempt}

SI within the past 30 days and a lifetime history of SA at baseline were the strongest univariate predictors of subsequent 12-month SA. SA was unrelated to race; however, SA was more likely among women and younger patients and less likely among patients who completed high school. All 5 psychiatric symptoms assessed by the ASI at baseline predicted increased odds of subsequent SA. SA was more common among patients with daily stimulant use, any nicotine use, higher ASI drug scores, and more days using alcohol or drugs at baseline. Higher odds of SA were predicted by emergency

Table 2. Suicidal Ideation and Suicide Attempt Incidence over 12-Month Follow-up After Screening and Brief Intervention for Substance Use

\begin{tabular}{ccccccc}
\hline & & & & \multicolumn{2}{c}{ Incidence (\%) } \\
\cline { 5 - 7 } & & & & & & \\
\cline { 5 - 7 } & Present (n) & Absent (n) & Missing Data (n) & Rate & $95 \%$ CI \\
\hline SI & 187 & 534 & 147 & 25.9 & $22.8-29.3$ \\
SA & 55 & 725 & 88 & 7.1 & $6.0-9.9$ \\
\hline
\end{tabular}

CI, confidence interval; SA, suicide attempt; SI, suicide ideation. 
Table 3. Univariate Predictors of Suicidal Ideation and Suicide Attempt

\begin{tabular}{|c|c|c|c|c|c|c|c|c|}
\hline \multirow[b]{2}{*}{ Baseline Variable } & \multicolumn{4}{|c|}{ By 12-Month SI } & \multicolumn{4}{|c|}{ By 12-Month SA } \\
\hline & $\begin{array}{l}\text { SI Present } \\
(\mathrm{n}=187)\end{array}$ & $\begin{array}{l}\text { SI Absent } \\
(\mathrm{n}=534)\end{array}$ & OR & $P$ Value & $\begin{array}{l}\text { SA Present } \\
(\mathrm{n}=55)\end{array}$ & $\begin{array}{l}\text { SA Absent } \\
(\mathrm{n}=725)\end{array}$ & OR & $P$ Value \\
\hline \multicolumn{9}{|l|}{ Demographic } \\
\hline Age (years), mean (SD) & $47.2(10.7)$ & $48.5(10.8)$ & 0.89 & .15 & $44.8(11.5)$ & $48.2(10.6)$ & 0.74 & .03 \\
\hline Female sex & $61(32.6)$ & $174(32.6)$ & 1.00 & .98 & $26(47.3)$ & $222(30.6)$ & 1.94 & .02 \\
\hline White & $90(48.1)$ & $223(41.8)$ & 1.34 & .07 & $20(36.4)$ & $321(44.3)$ & 0.73 & .28 \\
\hline African American & $58(31.0)$ & $214(40.1)$ & 0.66 & .02 & $24(43.6)$ & $268(37.0)$ & 1.25 & .43 \\
\hline Other race & $39(20.9)$ & $97(18.2)$ & 1.14 & .53 & $11(20.0)$ & $136(18.8)$ & 1.15 & .68 \\
\hline $\begin{array}{l}\text { Hispanic ethnicity (any } \\
\text { race) }\end{array}$ & $18(9.6)$ & $38(7.1)$ & 1.31 & .37 & $4(7.3)$ & $61(8.4)$ & 0.81 & .69 \\
\hline High school graduate & $145(77.5)$ & $446(83.5)$ & 0.74 & .15 & $34(61.8)$ & $600(82.9)$ & 0.36 & $<.001$ \\
\hline Married or cohabitating & $36(19.3)$ & $94(17.7)$ & 1.02 & .92 & $10(18.2)$ & $130(18.0)$ & 0.93 & .84 \\
\hline \multicolumn{9}{|l|}{ Employment and social } \\
\hline Unemployed & $152(81.3)$ & $390(73.3)$ & 1.64 & .01 & $46(83.6)$ & $541(74.9)$ & 1.70 & .16 \\
\hline Receiving welfare & $136(72.7)$ & $373(70.0)$ & 1.22 & .29 & $38(69.1)$ & $513(70.9)$ & 0.87 & .64 \\
\hline Waiting legal charges & $9(4.8)$ & $29(5.5)$ & 0.91 & .79 & $5(9.3)$ & $40(5.5)$ & 1.83 & .21 \\
\hline Jail in the past 90 days & $11(5.9)$ & $25(4.7)$ & 1.37 & .40 & $5(9.1)$ & $40(5.5)$ & 1.66 & .30 \\
\hline $\begin{array}{l}\text { Homeless in the past } 90 \\
\text { days }\end{array}$ & $53(28.5)$ & $148(27.8)$ & 1.08 & .66 & $18(32.7)$ & $212(29.3)$ & 1.18 & .57 \\
\hline \multicolumn{9}{|l|}{ Psychiatric symptoms } \\
\hline Depression & $155(82.9)$ & $300(56.2)$ & 3.56 & $<.001$ & $47(85.5)$ & $449(61.9)$ & 3.17 & .002 \\
\hline Anxiety & $156(83.4)$ & $306(57.3)$ & 3.55 & $<.001$ & $46(83.6)$ & $459(63.3)$ & 2.70 & .01 \\
\hline Hallucinations & $29(15.6)$ & $34(6.4)$ & 2.53 & $<.001$ & $11(20.0)$ & $61(8.4)$ & 2.66 & .01 \\
\hline Concentration & $128(68.4)$ & $220(41.2)$ & 3.06 & $<.001$ & $38(69.1)$ & $340(46.9)$ & 2.45 & .003 \\
\hline Violent behavior & $47(25.1)$ & $58(10.9)$ & 2.59 & $<.001$ & $23(41.8)$ & $96(13.2)$ & 4.43 & $<.001$ \\
\hline \multicolumn{9}{|l|}{ Suicidality } \\
\hline $\begin{array}{l}\text { Suicidal ideation in the } \\
\text { past } 30 \text { days (at } \\
\text { baseline) }\end{array}$ & 70 (37.4) & $25(4.7)$ & 12.28 & $<.001$ & $24(43.6)$ & $71(9.8)$ & 6.78 & $<.001$ \\
\hline $\begin{array}{l}\text { Suicide attempt during } \\
\text { lifetime (at baseline) }\end{array}$ & $126(67.4)$ & $171(32.1)$ & 4.36 & $<.001$ & $44(80.0)$ & $266(36.7)$ & 6.39 & $<.001$ \\
\hline \multicolumn{9}{|l|}{$\begin{array}{l}\text { Substance use in the past } \\
30 \text { days }\end{array}$} \\
\hline Any alcohol & $120(64.2)$ & $384(71.9)$ & 0.69 & .03 & $34(61.8)$ & $510(70.3)$ & 0.69 & .20 \\
\hline Daily alcohol & $12(6.4)$ & $43(8.1)$ & 0.73 & .35 & $4(7.3)$ & $56(7.7)$ & 0.90 & .84 \\
\hline Any opiate & $58(31.0)$ & $139(26.0)$ & 1.36 & .10 & $18(32.7)$ & $193(26.6)$ & 1.39 & .27 \\
\hline Daily opiate & $3(1.6)$ & $7(1.3)$ & 1.62 & .46 & $0(0.0)$ & $10(1.4)$ & 0.00 & .99 \\
\hline $\begin{array}{l}\text { Any sedative/hypnotic/ } \\
\text { tranquilizer }\end{array}$ & $23(12.3)$ & $40(7.5)$ & 1.63 & .07 & $4(7.3)$ & $64(8.8)$ & 0.84 & .74 \\
\hline $\begin{array}{l}\text { Daily sedative/hypnotic/ } \\
\text { tranquilizer }\end{array}$ & $13(7.1)$ & $20(3.8)$ & 1.97 & .05 & $3(5.8)$ & $31(4.4)$ & 1.26 & .70 \\
\hline Any stimulant & $77(41.2)$ & $218(40.8)$ & 1.05 & .76 & $29(52.7)$ & $297(41.0)$ & 1.66 & .07 \\
\hline Daily stimulant & $11(5.9)$ & $11(2.1)$ & 3.57 & .003 & $6(10.9)$ & $17(2.3)$ & 5.26 & $<.001$ \\
\hline Any marijuana & $134(71.7)$ & $414(77.5)$ & 0.74 & .12 & $39(70.9)$ & $549(75.7)$ & 0.82 & .51 \\
\hline Daily marijuana & $26(13.9)$ & $93(17.4)$ & 0.78 & .28 & $12(21.8)$ & $116(16.0)$ & 1.52 & .21 \\
\hline Any nicotine & $138(73.8)$ & $375(70.5)$ & 1.24 & .26 & $46(83.6)$ & $511(70.7)$ & 2.02 & .07 \\
\hline Daily nicotine & $102(54.5)$ & $270(50.8)$ & 1.25 & .21 & $36(65.5)$ & $369(51.0)$ & 1.78 & .05 \\
\hline \multicolumn{8}{|l|}{ ASI, mean (SD) } & .72 \\
\hline Alcohol score & $0.16(0.21)$ & $0.14(0.19)$ & 1.08 & .33 & $0.15(0.22)$ & $0.15(0.20)$ & 1.01 & .97 \\
\hline Drug score & $0.15(0.12)$ & $0.12(0.10)$ & 1.29 & .002 & $0.17(0.14)$ & $0.13(0.11)$ & 1.50 & .002 \\
\hline
\end{tabular}


Table 3. Continued

\begin{tabular}{|c|c|c|c|c|c|c|c|c|}
\hline \multirow[b]{2}{*}{ Baseline Variable } & \multicolumn{4}{|c|}{ By 12-Month SI } & \multicolumn{4}{|c|}{ By 12-Month SA } \\
\hline & $\begin{array}{l}\text { SI Present } \\
(\mathrm{n}=187)\end{array}$ & $\begin{array}{l}\text { SI Absent } \\
(\mathrm{n}=534)\end{array}$ & OR & $P$ Value & $\begin{array}{l}\text { SA Present } \\
(\mathrm{n}=55)\end{array}$ & $\begin{array}{l}\text { SA Absent } \\
(\mathrm{n}=725)\end{array}$ & OR & $P$ Value \\
\hline $\begin{array}{l}\text { Days using alcohol or } \\
\text { drugs (of past 30), } \\
\text { mean (SD) }\end{array}$ & $16.0(11.3)$ & $15.4(11.4)$ & 1.08 & .36 & $18.8(11.3)$ & $15.1(11.4)$ & 1.43 & .01 \\
\hline \multicolumn{9}{|l|}{$\begin{array}{l}\text { Medical, psychiatric, and } \\
\text { substance use } \\
\text { treatment in the past } \\
90 \text { days }\end{array}$} \\
\hline Substance use treatment & $14(7.6)$ & $32(6.0)$ & 1.19 & .58 & $4(7.3)$ & $50(7.0)$ & 1.01 & .98 \\
\hline 12-Step participation & $38(20.3)$ & $84(15.7)$ & 1.40 & .12 & $9(16.4)$ & $125(17.2)$ & 0.94 & .87 \\
\hline Emergency department & $86(46.2)$ & $228(42.7)$ & 1.20 & .31 & $34(63.0)$ & $311(42.9)$ & 2.25 & .01 \\
\hline Medical visit & $147(79.5)$ & $439(82.5)$ & 0.83 & .37 & $42(77.8)$ & $586(81.2)$ & 0.80 & .51 \\
\hline Psychiatric outpatient & $80(43.0)$ & $113(21.2)$ & 2.70 & $<.001$ & $21(38.2)$ & $182(25.2)$ & 1.75 & .05 \\
\hline \multicolumn{9}{|l|}{$\begin{array}{c}\text { EuroQol health-related } \\
\text { quality of life }\end{array}$} \\
\hline Mobility impairment & $126(67.7)$ & $280(52.4)$ & 1.89 & $<.001$ & $42(76.4)$ & $402(55.5)$ & 2.33 & .01 \\
\hline Self-care impairment & $33(17.7)$ & $84(15.7)$ & 1.16 & .50 & $11(20.0)$ & $115(15.9)$ & 1.28 & .48 \\
\hline $\begin{array}{l}\text { Usual activity } \\
\text { impairment }\end{array}$ & $117(62.9)$ & $229(42.9)$ & 2.11 & $<.001$ & $38(69.1)$ & $333(46.0)$ & 2.31 & .004 \\
\hline Pain & $153(82.3)$ & $423(79.2)$ & 1.31 & .21 & $43(78.2)$ & $575(79.4)$ & 0.95 & .87 \\
\hline Anxiety or depression & $139(74.7)$ & $242(45.4)$ & 3.45 & $<.001$ & $42(76.4)$ & $374(51.7)$ & 2.70 & .002 \\
\hline $\begin{array}{l}\text { Visual-Analogue Health } \\
\text { Scale, mean }(S D)\end{array}$ & $55(24.0)$ & $63(22.3)$ & 0.73 & $<.001$ & $50(24.6)$ & $62(22.6)$ & 0.63 & $<.001$ \\
\hline
\end{tabular}

Data are $\mathrm{n}(\%)$ unless otherwise indicated. Counts include participants with available baseline measures and suicide ideation (SI) and suicide attempt (SA) data at follow-up. Variables with significant univariate associations are presented in boldface.

ASI, Addiction Severity Index Lite; OR, odds ratio; SD, standard deviation.

department and psychiatric outpatient treatment within the past 90 days at baseline, but not other medical and substance abuse treatment service utilization. EuroQol impairment in mobility, usual activities, and anxiety or depression were associated with greater odds of SA; higher perceived health status was associated with lower odds of SA.

\section{Multiple Regression Predictors of SI and SA}

Multiple regression models tested which baseline predictors were associated with subsequent 1-year SI and SA after accounting for other predictors (Table 4). Only the predictors with significant simple associations with SI or SA were included in these models, with 2 exceptions: any nicotine use within the past 30 days was omitted because of strong overlap with daily nicotine use, and alcohol use within the past 30 days was omitted because of its association with greater suicide risk among the general population, making it unlikely to be considered a protective factor.

When controlling for other variables, 12-month SI was predicted by SI within the past 30 days, lifetime SA, and EuroQol depression/anxiety at baseline. Twelve-month SA was predicted by difficulty with violent behavior, SI within the past 30 days, and lifetime SA at baseline. Substance use, treatment utilization, and demographic variables did not significantly predict SI or SA beyond what was accounted for by other variables.

\section{Discussion}

This study examined SI and SA over 12 months after patients with recent substance use received primary care in public, urban clinics. Incidence rates of SI $(25.9 \%)$ and SA (7.1\%) were considerably higher than estimated 1-year incidence rates for people in the general US population (SI, 3.7\%; $\mathrm{SA}, 0.5 \%),{ }^{33}$ which is consistent with research indicating that substance use is a substantial risk factor for suicidality. ${ }^{5,15-18}$ While variables reflecting substance use only occasionally predicted SI and SA within this sample (including a small, yet surprising association between alcohol use and lower SI risk), it is important that these findings be interpreted 
Table 4. Multiple Regression Predictors of Suicidal Ideation and Suicide Attempt

\begin{tabular}{|c|c|c|c|c|c|c|}
\hline \multirow[b]{2}{*}{ Baseline Variable } & \multicolumn{3}{|c|}{ 12-Month SI } & \multicolumn{3}{|c|}{ 12-Month SA } \\
\hline & OR & $95 \% \mathrm{CI}$ & $P$ Value & OR & $95 \% \mathrm{CI}$ & $P$ Value \\
\hline Age & 1.02 & $0.82-1.26$ & .85 & 0.77 & $0.54-1.11$ & .16 \\
\hline Female sex & 0.82 & $0.54-1.24$ & .34 & 1.50 & $0.76-2.96$ & .25 \\
\hline African American & 0.85 & $0.54-1.33$ & .47 & 1.83 & $0.91-3.70$ & .09 \\
\hline High school graduate & 0.85 & $0.50-1.44$ & .55 & 0.52 & $0.26-1.04$ & .07 \\
\hline Unemployed & 1.04 & $0.62-1.73$ & .88 & 1.20 & $0.48-3.02$ & .70 \\
\hline Depression & 1.05 & $0.58-1.90$ & .87 & 1.01 & $0.39-2.61$ & .98 \\
\hline Anxiety & 1.60 & $0.89-2.88$ & .11 & 0.66 & $0.24-1.84$ & .43 \\
\hline Hallucinations & 1.25 & $0.62-2.52$ & .54 & 1.12 & $0.45-2.79$ & .80 \\
\hline Concentration & 1.40 & $0.86-2.26$ & .17 & 1.03 & $0.47-2.28$ & .94 \\
\hline Violent behavior & 1.24 & $0.74-2.09$ & .41 & 2.21 & $1.10-4.42$ & .03 \\
\hline SI in the past 30 days (at baseline) & 6.05 & $3.40-10.76$ & $<.001$ & 3.69 & $1.72-7.93$ & $<.001$ \\
\hline SA during lifetime (at baseline) & 2.66 & $1.76-4.02$ & $<.001$ & 3.52 & $1.60-7.78$ & .002 \\
\hline Daily stimulant use in the past 30 days & 2.37 & $0.79-7.14$ & .12 & 1.86 & $0.46-7.43$ & .38 \\
\hline Daily nicotine in the past 30 days & 0.96 & $0.62-1.48$ & .86 & 1.32 & $0.66-2.66$ & .43 \\
\hline ASI drug score & 1.07 & $0.82-1.41$ & .61 & 1.04 & $0.68-1.58$ & .86 \\
\hline Days using alcohol or drugs (of past 30 ) & 0.97 & $0.74-1.28$ & .85 & 1.17 & $0.78-1.74$ & .44 \\
\hline Emergency department in the past 90 days & 0.75 & $0.49-1.16$ & .20 & 1.66 & $0.82-3.37$ & .16 \\
\hline Psychiatric outpatient in the past 90 days & 1.41 & $0.90-2.21$ & .13 & 1.38 & $0.68-2.81$ & .37 \\
\hline \multicolumn{7}{|l|}{ EuroQol } \\
\hline Mobility impairment & 1.32 & $0.84-2.09$ & .23 & 1.15 & $0.55-2.40$ & .70 \\
\hline Usual activity impairment & 1.16 & $0.71-1.91$ & .55 & 1.14 & $0.52-2.50$ & .73 \\
\hline Depression or anxiety & 1.78 & $1.07-2.96$ & .03 & 1.10 & $0.48-2.54$ & .81 \\
\hline Visual-Analogue Health Scale & 1.06 & $0.86-1.31$ & .57 & 0.85 & $0.61-1.19$ & .35 \\
\hline
\end{tabular}

Variables with significant associations are presented in boldface.

ASI, Addiction Severity Index Lite; CI, confidence interval; OR, odds ratio; SA, suicide attempt; SI, suicide ideation.

within the context of the present sample, which had markedly high suicidality in general. That is, while substance use variables did not predict which patients within this sample had particularly elevated risk, the sample as a whole had considerably high rates of SI and SA, suggesting that alcohol and drug use may still be associated with elevated risk for suicidality, although patients using alcohol in this study had slightly lower relative odds of suicidality than those who used drugs only. It should be noted that additional risk factors that frequently co-occur with substance use, including homelessness, unemployment, frequent medical service utilization, and psychiatric complaints, could also have contributed to the high SI and SA rates observed.

Several baseline variables had univariate associations with subsequent SI and SA, which may indicate subpopulations of substance-using primary care patients who are at a particularly elevated risk for SI and SA. These were often consistent with known risk factors, including physical and psychi- atric health complaints, ${ }^{22-24}$ daily stimulant use, ${ }^{17}$ violent behavior, ${ }^{19}$ and previous SI or SA. ${ }^{23}$ After controlling for overlap among risk factors through multiple logistic regression, SI and SA were both predicted by SI within the past 30 days and lifetime SA; SI was also predicted by EuroQol depression/anxiety and SA was also predicted by difficulties with violent behavior. These findings may help primary care providers identify which patients are at greatest risk. Nonetheless, suicidality is challenging to predict, and using these variables alone to assess suicide risk would inadequately predict actual suicidality outcomes for many patients. For example, most participants endorsing SI at baseline did not have subsequent SA, and conversely, fewer than half of patients who reported SA over the 1-year follow-up period endorsed SI within the past 30 days at baseline. In other words, it would be very challenging for providers to predict who will subsequently ideate or attempt suicide and when that will happen. Additional research may help in 
understanding risk factors for suicide in substance-using primary care patients.

People who use drugs are more likely to interact with primary care providers than with specialty addiction or mental health providers, ${ }^{11}$ giving primary care providers unique opportunities to intervene in both substance use and suicide. However, these opportunities are often missed. ${ }^{34}$ Given the burden that primary care providers have of screening for multiple health conditions, we are cautious about recommending yet another screen. However, a case could be made for proactive, episodic assessment of suicidality for primary care patients who use drugs as a critical step for preventing suicide within this high-risk population. This recommendation is consistent with increasing practices of screening for suicidality among patients with major depression, and it is consistent with national organizations' recommendations to screen and assess suicidality, and provide triage services for suicidal patients in primary care. ${ }^{35,36} \mathrm{We}$ recognize that providers may be reluctant to screen for suicidality when adequate treatment and referral sources are not readily available; therefore, a case could also be made for additional research on effective ways to improve resources for addressing suicidality within primary care, especially in settings with high rates of illicit substance use.

Additional research testing integrated protocols for treating suicidality and substance use simultaneously within primary care is warranted, as has been undertaken for co-occurring suicidality and depression. ${ }^{37}$ The relationship between substance use and suicidality is likely multifaceted and multidirectional and may require specific considerations for patients with problems in both areas. For example, intoxication can increase acute risk for suicide, but additional factors such as depression, impulsivity, homelessness, and limited social support may both exacerbate and be exacerbated by drug use and suicidality. ${ }^{38-40}$

This study has noteworthy limitations. First, the assessment battery was relatively small. Although this intentionally had the practical benefit of mirroring brief assessments that could be used in primary care, it may have led us to miss additional risk factors for suicidality. Likewise, several mental health constructs were measured using single-item questions (eg, anxiety and depression), which limited the ability to represent these constructs as complex, multifaceted conditions. We did not in- clude a non-substance-using control group, limiting our ability to compare rates of SI and SA against non-substance-using samples from the same clinics. The ASI used different time intervals for assessing SI (past 30 days) and SA (since the last assessment) during the follow-up period, and this difference may confound the different findings between SI and SA. For example, the ASI may not have detected SI that occurred more than 30 days before a follow-up assessment, suggesting that actual SI rates during the full 12-month follow-up could be higher than what was reported here. Seven participants were excluded because of imminent suicidality at baseline, which restricted the sample and may have therefore also underestimated SI and SA rates in this population. Finally, we did not assess completed suicide, and it is possible that some variables associated with SI or SA are differently related with risk for suicide completion.

Strengths of the study include prospective examination of suicidality over a 1 -year period, the use of brief measures that are suitable for primary care settings, and the use of an understudied sample of primary care patients with recent substance use and significant medical, psychiatric, and psychosocial impairments.

\section{Conclusions}

Substance-using individuals in public primary care clinics are at increased risk of SI and SAs. We recommend episodically assessing suicidality among primary care patients who use illicit substances or prescription medications for nonmedical purposes, which is consistent with existing recommendations and trends for increased assessment of suicidality in primary care. For patients who use substances, risk for subsequent suicidality is particularly elevated among those with recent SI, any lifetime SA, or difficulty with depression, anxiety, or violent behavior.

The authors thank the research assistants, research coordinators, patients, clinicians, and administrative staff who made this study possible.

To see this article online, please go to: http://jabfm.org/content/ 30/2/150. full.

\section{References}

1. Centers for Disease Control and Prevention. Injury prevention \& control: data and statistics (WISQARS). Atlanta: National Center for Injury Prevention and Control; 2015. Available from: 
http://www.cdc.gov/injury/wisqars/leading_causes_ death.html. Accessed March 23, 2016.

2. Curtin SC, Warner M, Hedegaard H. Increase in suicide in the United States, 1999-2014. National Center for Health Statistics. NCHS data brief no. 241. April 2016. Available from: http://www.cdc. gov/nchs/products/databriefs/db241.htm. Accessed July 20, 2016.

3. Centers for Disease Control and Prevention. Suicide: Consequences. Atlanta, GA: National Center for Injury Prevention and Control; 2016. Available from: https://www.cdc.gov/violenceprevention/ suicide/consequences.html.

4. Comtois KA, Kerbrat AH, Atkins DC, Roy-Byrne P, Katon WJ. Self-reported usual care for self-directed violence during the six months prior to emergency department admission. Med Care 2015;53:45-53.

5. Preuss UW, Schuckit MA, Smith TL, et al. Comparison of 3190 alcohol-dependent individuals with and without suicide attempts. Alcohol Clin Exp Res 2002;26:471-7.

6. Tondo L, Baldessarini RJ, Hennen J, et al. Suicide attempts in major affective disorder patients with comorbid substance use disorders. J Clin Psychiatry 1999;60(Suppl 2):63-9.

7. Yuodelis-Flores C, Ries RK. Addiction and suicide: a review. Am J Addict 2015;24:98-104.

8. Nock MK, Hwang I, Sampson NA, Kessler RC. Mental disorders, comorbidity and suicidal behavior: results from the National Comorbidity Survey Replication. Mol Psychiatry 2010;15:868-76.

9. McLellan AT, Woodworth AM. The affordable care act and treatment for "substance use disorders": implications of ending segregated behavioral healthcare. J Subst Abuse Treat 2014;46:541-5.

10. Reid MC, Fiellin DA, O'Connor PG. Hazardous and harmful alcohol consumption in primary care. Arch Intern Med 1999;159:1681-9.

11. Wang PS, Lane M, Olfson M, Pincus HA, Wells $\mathrm{KB}$, Kessler RC. Twelve-month use of mental health services in the United States: results from the National Comorbidity Survey Replication. Arch Gen Psychiatry 2005;62:629-40.

12. Bakken K, Vaglum P. Predictors of suicide attempters in substance-dependent patients: a six-year prospective follow-up. Clin Pract Epidemiol Ment Health 2007;3:20.

13. Britton PC, Stephens B, Wu J, et al. Comorbid depression and alcohol use disorders and prospective risk for suicide attempt in the year following inpatient hospitalization. J Affect Disord 2015;187:151-5.

14. Carmel A, Ries R, West II, Bumgardner K, Roy-Byrne P. Suicide risk and associated demographic and clinical correlates among primary care patients with recent drug use. Am J Drug Alcohol Abuse 2016;42:351-7.

15. Artenie AA, Bruneau J, Roy É, et al. Licit and illicit substance use among people who inject drugs and the association with subsequent suicidal attempt: substance use and suicide attempt among PWID. Addiction 2015;110:1636-43.

16. Cottler LB, Campbell W, Krishna VAS, Cunningham-Williams RM, Abdallah AB. Predictors of high rates of suicidal ideation among drug users. J Nerv Ment Dis 2005;193:431.

17. Garlow SJ, Purselle D, D'Orio B. Cocaine use disorders and suicidal ideation. Drug Alcohol Depend 2003;70:101-4.

18. Vaszari JM, Bradford S, Callahan O'Leary C, Ben Abdallah A, Cottler LB. Risk factors for suicidal ideation in a population of community-recruited female cocaine users. Compr Psychiatry 2011;52:238-46.

19. Conner KR, Cox C, Duberstein PR, Tian L, Nisbet PA, Conwell Y. Violence, alcohol, and completed suicide: a case-control study. Am J Psychiatry 2001; 158:1701-5.

20. Krupski A, Joesch JM, Dunn C, et al. Testing the effects of brief intervention in primary care for problem drug use in a randomized controlled trial: rationale, design, and methods. Addict Sci Clin Pract 2012;7:27.

21. Roy-Byrne P, Bumgardner K, Krupski A, et al. Brief intervention for problem drug use in safety-net primary care settings: a randomized clinical trial. JAMA 2014;312:492-501.

22. Crump C, Sundquist K, Sundquist J, Winkleby MA. Sociodemographic, psychiatric and somatic risk factors for suicide: a Swedish national cohort study. Psychol Med 2014;44:279-89.

23. Haukka J, Suominen K, Partonen T, Lönnqvist J. Determinants and outcomes of serious attempted suicide: a nationwide study in Finland, 1996-2003. Am J Epidemiol 2008;167:1155-63.

24. Kontaxakis VP, Christodoulou GN, Mavreas VG, Havaki-Kontaxaki BJ. Attempted suicide in psychiatric outpatients with concurrent physical illness. Psychother Psychosom 1988;50:201-6.

25. Chang S-S, Stuckler D, Yip P, Gunnell D. Impact of 2008 global economic crisis on suicide: time trend study in 54 countries. BMJ 2013;347:f5239.

26. Carmel A, Ries R, West II, Bumgardner K, RoyByrne P. Suicide risk and associated demographic and clinical correlates among primary care patients with recent drug use. Am J Drug Alcohol Abuse 2016;42:361-7.

27. Cacciola JS, Alterman AI, McLellan AT, Lin Y-T, Lynch KG. Initial evidence for the reliability and validity of a "Lite" version of the Addiction Severity Index. Drug Alcohol Depend 2007;87:297-302.

28. Yudko E, Lozhkina O, Fouts A. A comprehensive review of the psychometric properties of the Drug Abuse Screening Test. J Subst Abuse Treat 2007;32:189-98.

29. EuroQol Group. EuroQol-a new facility for the measurement of health-related quality of life. Health Policy 1990;16:199-208.

30. van Buuren S, Groothuis-Oudshoorn K. mice: Multivariate imputation by chained equations in R. J Stat Softw 2011;45:1-68. 
31. Hallgren KA, Witkiewitz K, Kranzler HR, et al. In conjunction with the Alcohol Clinical Trials Initiative (ACTIVE) Workgroup. Missing data in alcohol clinical trials with binary outcomes. Alcohol Clin Exp Res 2016;40:1548-57.

32. R Core Team. R: a language and environment for statistical computing. Vienna, Austria: R Foundation for Statistical Computing; 2015.

33. Crosby AE, Han B, Ortega LA, Parks SE, Gfroerer J. Centers for Disease Control and Prevention (CDC). Suicidal thoughts and behaviors among adults aged $\geq 18$ years-United States, 2008-2009. MMWR Surveill Summ 2011;60:1-22.

34. Denneson LM, Kovas AE, Britton PC, Kaplan MS, McFarland BH, Dobscha SK. Suicide risk documented during veterans' last Veterans Affairs health care contacts prior to suicide. Suicide Life Threat Behav 2016;46:363-74.

35. Office of the Surgeon General. National strategy for suicide prevention: goals and objectives for action, 2012. A report of the U.S. Surgeon General and of the National Action Alliance for Suicide Prevention. Bethesda, MD: US Department of
Health \& Human Services; 2012. Available from: http://www.surgeongeneral.gov/library/reports/ national-strategy-suicide-prevention/. Accessed January 21, 2017.

36. Goldsmith SK. Reducing suicide: a national imperative. Washington, DC: National Academies Press; 2002.

37. Alexopoulos GS, Reynolds CF, Bruce ML, et al. Reducing suicidal ideation and depression in older primary care patients: 24-month outcomes of the PROSPECT study. Am J Psychiatry 2009;166: 882-90.

38. Gorlyn M. Impulsivity in the prediction of suicidal behavior in adolescent population. Int J Adolesc Med Health 2011;17:205-10.

39. Taylor PJ, Gooding PA, Wood AM, Johnson J, Tarrier N. Prospective predictors of suicidality: defeat and entrapment lead to changes in suicidal ideation over time. Suicide Life Threat Behav 2011;41:297306.

40. Galway K, Gossrau-Breen D, Mallon S, et al. Substance misuse in life and death in a 2-year cohort of suicides. Br J Psychiatry 2016;208:292-7. 